\title{
Internet-based recruitment system for HIV and STI screening for men who have sex with men in Estonia, 2013: analysis of preliminary outcomes
}

K Rüütel (kristi.ruutel@tai.ee) ${ }^{1}$, L Lõhmus ${ }^{1}$, J Jänes²

1. Infectious Diseases and Drug Monitoring Department, National Institute for Health Development, Tallinn, Estonia

2. Quattromed HTI Laborid OÜ, Tallinn, Estonia

The aim of the current project was to develop an Internet-based recruitment system for HIV and sexually transmitted infection (STI) screening for men who have sex with men (MSM) in Estonia in order to collect biological samples during behavioural studies. In 2013, an Internet-based HIV risk-behaviour survey was conducted among MSM living in Estonia. After completing the questionnaire, all participants were offered anonymous and free-of-charge STI testing. They could either order a urine sample kit by post to screen for chlamydia infections (including lymphogranuloma venereum (LGV)), trichomoniasis, gonorrhoea and Mycoplasma genitalium infections, or visit a laboratory for HIV, hepatitis A virus, hepatitis B virus, hepatitis $C$ virus and syphilis screening. Of 301 participants who completed the questionnaire, 265 (88\%), reported that they were MSM. Of these 265 MSM, 68 (26\%) underwent various types of testing. In the multiple regression analysis, Russian as the first language, previous HIV testing and living in a city or town increased the odds of testing during the study. Linking Internet-based behavioural data collection with biological sample collection is a promising approach. As there are no specific STI services for MSM in Estonia, this system could also be used as an additional option for anonymous and free-of-charge STI screening.

\section{Background}

Men who have sex with men (MSM) continue to be one of the groups at highest risk for HIV and sexually transmitted infections (STI) in the European Union. MSM made up the highest proportion of total number of HIV cases in Europe in 2013 (42\%), and in 2012 more than a third of reported gonorrhoea cases in Europe were in $\operatorname{MSM}(38 \%)[1,2]$.

In 2013, Estonia had a total population of around 1.3 million, and 24.6 newly diagnosed HIV cases and 1.8 AIDS cases per 100,000 population [3]. It has been estimated that there are about 9,000 MSM in Estonia [4]. Triangulation of data from various studies suggests that HIV prevalence in MSM could be around 2-3\% [5]. No data are available on STI prevalence in MSM or the proportion of reported STI cases that are in MSM.

Gathering accurate data on HIV prevalence and risk behaviours in MSM has posed a challenge for researchers in Estonia [6]. For HIV-prevalence estimations, 59 MSM were recruited by using respondent-driven sampling (RDS) [6] and 79 by convenience sampling in gay venues and community-based organisations [7]. These sampling methods did not yield the desired sample size. At the same time, MSM participation in four consecutive Internet studies (2004, 2006, 2007 and 2010) has been relatively high, especially in the European MSM Internet Study (EMIS) [8-11]. Unfortunately, the Internet does not offer the opportunity to gather biological material for testing to estimate HIV/STI prevalence rates.

In other countries, studies of MSM as well as of the general population have shown that Internet-based screening and self-sampled postal testing for STIs is an effective, acceptable and feasible approach [12-16]. Our aim was to develop an Internet-based recruitment system for HIV and STI screening for MSM in order to collect biological samples during behavioural studies.

\section{Methods}

We conducted an Internet-based study of MSM to investigate sexual and drug-use behaviours, previous HIV/STI testing, mental health, internalised homonegativity and HIV/STI related knowledge and attitudes among this population group. The eligibility criteria included: self-identifying as male; living in Estonia; age of 18 years or older; and being sexually attracted to men and/or having ever had sex with a man. Taking into account the range of response rates in previous studies, the planned sample size was 300 [8-11]. 


\section{Questionnaire}

The questionnaire was constructed using Internet survey software (http://www.limesurvey.org/). The questionnaire was presented over 63 web pages and included 144 questions. It took around 45 minutes to complete. To minimise completion time, it was tailored with intra-questionnaire filters. For example, specific questions regarding HIV testing and treatment were not shown if the participant had already stated that they had never been tested for HIV or were HIV-negative. The questionnaire was accessible online from April to September 2013. All study materials were available in both Estonian and Russian (25\% of the population of Estonia is predominantly Russian-speaking [17]). The questionnaire's design was based on previous Estonian and international experiences [7-11, 18] and included the following domains:

- Sociodemographic data.

- Sexual orientation (homosexual, bisexual, straight, heterosexual, any other term (please specify) or 'I don't usually use a term/define myself'), type of relationship, and sexual behaviour.

- HIV and STI testing and history. To assess HIV testing history, we asked: 'Have you ever been tested for HIV?' and 'What was the result of your last HIV test?' To assess STI testing history, we asked: 'Have you ever been tested for any STI (for example syphilis, gonorrhoea, chlamydia, trichomoniasis, genital herpes)?'; 'Have you ever been diagnosed with any STI (for example syphilis, gonorrhoea, chlamydia, trichomoniasis, genital herpes)?'; and 'Have you ever had anal swabs taken for STI diagnosis?'

- Confidence about HIV and STI testing possibilities was assessed with the following two questions 'How confident are you that you could get an HIV test if you wanted one?' and 'How confident are you that you could get a test for STIs (other than HIV) if you thought you needed it?' [11]. Responses were indicated by using a four-point Likert-type scale ( $1=$ very confident, $4=$ not at all confident).

- Illegal drug use and alcohol use (CAGE questionnaire) [19]. The CAGE questionnaire is widely used to screen patients with alcohol abuse or dependence in the general population as well as in clinical samples. It includes four yes/no items. Subjects who responded affirmatively to two or more questions were classified as CAGE-positive (problem drinkers with high likelihood of the presence of alcoholism).

- Internalised homonegativity. We used a short form of the 'Reactions to Homosexuality' scale [20, 21] that included seven of the original items loading on three factors: personal comfort with a gay identity, social comfort with gay men, and public identification as gay. Responses were indicated by using a seven-point Likert-type scale ( $0=$ strongly disagree, $6=$ strongly agree). All the items were coded at analysis so that a higher score indicated higher internalised homonegativity. The scale was additive, ranging from o to 6 .

- Contacts with HIV prevention services, HIV/STI knowledge and attitudes to HIV, STIs and related issues.

\section{Recruitment and promotion}

The study was promoted through Estonia-based gay online social media, gay community organisations, the national network of anonymous HIV testing sites and youth counselling centres. A special Facebook page was created to promote the study. The English version of the slogan of the study was 'Good health: the pride of every man!' Advertisements directed users to the opening page of the study. The opening page described the study aims and informed potential participants that their data would be anonymous, that no IP addresses were saved, and that the survey software installed no cookies or other trace files on computers. The participants could not pause the process of filling in the questionnaire and sign in later to finish it. Not collecting IP addresses meant that it was possible for one person to submit two or more questionnaires.

Testing for HIV and STIs and reporting of the results All the participants were offered voluntary, anonymous and free-of-charge HIV and STI testing for HIV, hepatitis $C$ virus ( $\mathrm{HCV}$ ), hepatitis $B$ virus (HBV), hepatitis A virus (HAV) and syphilis markers from blood, and for Neisseria gonorrhoeae, Trichomonas vaginalis, Chlamydia trachomatis (including lymphogranuloma venereum (LGV) genotyping) and Mycoplasma genitalia from urine sample.

After submitting the questionnaire, participants were referred to a landing page where each participant was assigned a unique study participation code (for example, u_aa1234) and detailed information, how to get tested and how the data were protected. For testing we used a special web-based testing service called Testikodus ('Test at Home' in English). This is an Internet portal run by Quattromed HTI Laborid OÜ (QM), which is the largest medical laboratory in Estonia. The portal offers anonymous fee-based testing for STIs. For the purposes of our study we created a special pathway for those who had filled in the study questionnaire to order test kits free of charge. There were two options to get tested and receive test results:

1. For blood-based testing (HIV, HCV, HBV, HAV and syphilis) the participants had to visit the QM laboratory in person (six sites in larger cities across Estonia, ranging from the capital city Tallinn (population 406,000, 2013) to Võru (population 12,800, 2013) [17]). The test results were available within five working days and could be received only by visiting the laboratory. Those who went to the laboratory could either return the urine sample kit by post or take the urine sample to the laboratory, depending on their preference. 
Participant flow chart and drop-out in various stages of the project, Internet study of men who have sex with men, Estonia, 2013

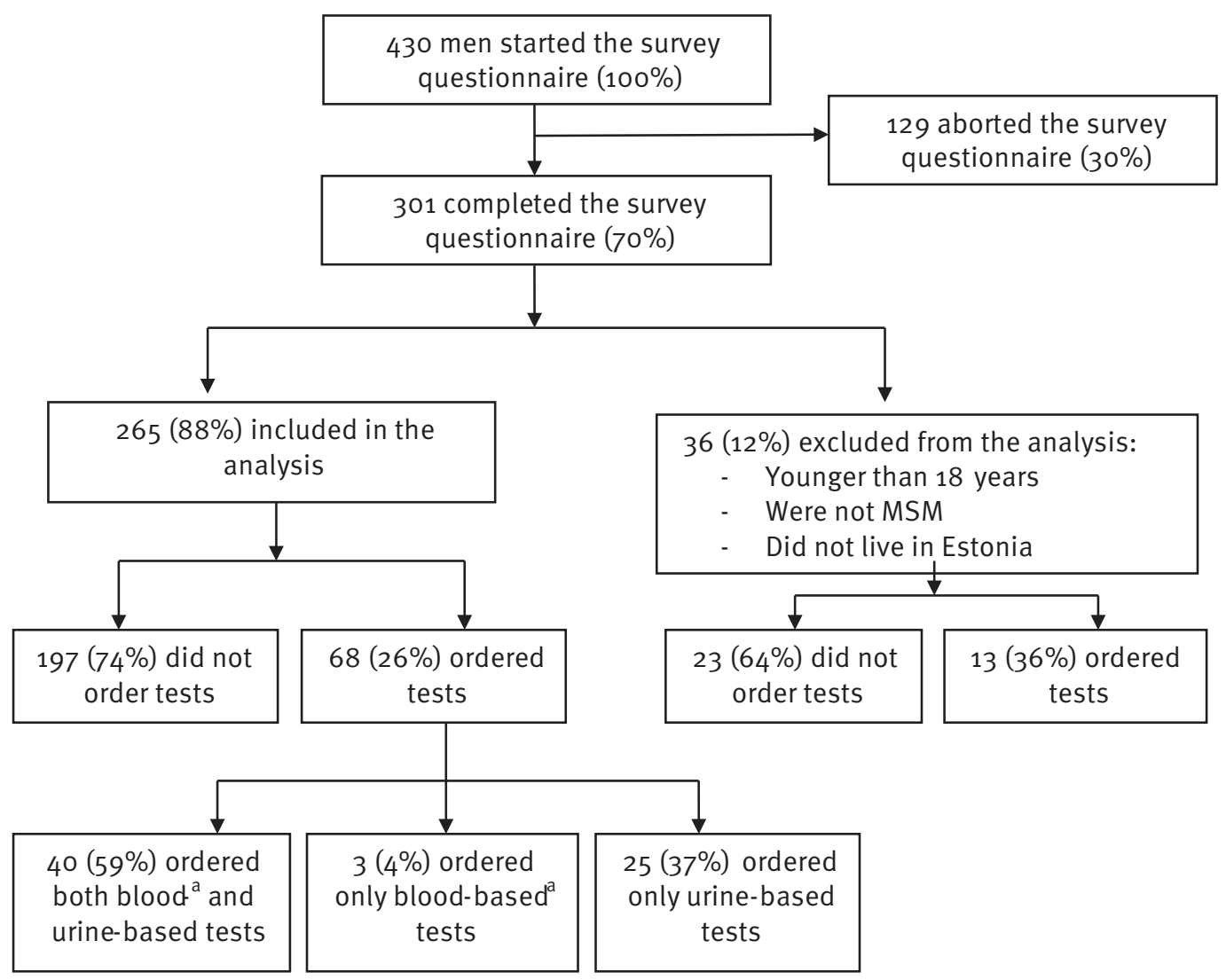

MSM: men who have sex with men.

Percentages are calculated on the basis of the previous cell

a Required a visit to the laboratory

2. For urine-based testing (gonorrhoea, trichomoniasis, chlamydia, LGV, and mycoplasmosis) the participants could order the urine sample kit to be delivered by SmartPOST courier services. For this they had to create an account in the Testikodus website using their unique study participation code. Participants were asked to give their email address and/or phone number, which were needed for the SmartPOST courier services. Through this account and emails the participants received confirmation once their order was successfully placed and the test results were ready. The test results were available within five working days and could be received through the Testikodus website account.

Testing could be carried out until 31 December 2013 in order to be included in the study.

If a participant tested positive for any of the urinebased tests, he was given information about where to go for treatment. Participants could attend one sexual health clinic in Tallinn anonymously and get treatment free of charge on presentation of the unique study participation code. If a participant tested positive for any of the blood-based tests, it was explained in the laboratory that these were screening tests and that the participant should go to an infectious diseases doctor for further tests to confirm the diagnosis. Due to the anonymous nature of the study we were not able to find out how many participants accessed confirmatory testing.

\section{Laboratory testing}

Ten $\mathrm{ml}$ of venous blood and/or $20 \mathrm{ml}$ of first void urine were collected from the participants. The following methods were used for infectious marker testing:

- HIV-antibodies and antigen (HIV 1,2 Ab+Ag), HCVantibodies (HCV Ab), anti-HAV IgM/IgG, HBsAg, and syphilis antibodies: chemiluminescence.

- Chlamydia (C. trachomatis, including LGV serovar), gonorrhea (N. gonorrhoeae), trichomoniasis (T. vaginalis) and mycoplasmosis (M. genitalium): PCR. 


\section{Data management and statistical analysis}

The data from the questionnaire and the unique participation codes (created in the Testikodus website and linked to the test results) were stored in different databases. The data were linked manually based on the date and time of day (e.g 10.07.2014 22:34) the participant submitted the questionnaire, and the date and time he reached the landing page (time difference approximately one second). The personal data necessary for ordering test kits (mobile phone numbers, email addresses, etc) were stored only on the Testikodus database and never linked to the data from anonymous questionnaires.

The statistical analyses were performed with Stata 11.0 (StataCorp LP, College Station, TX). Descriptive statistics were used to characterise participants. The dependent variable in our analyses was the fact of ordering either blood or urine-based tests. The associations between the participant's characteristics and dependent variables were evaluated using a Wilcoxon rank-sum test, a Fisher's exact test, or a one-way analysis of variance (ANOVA), followed by univariate and multivariable logistic regressions. For multivariable logistic regression, testing during the study was adjusted for age and factors significantly associated in the univariate analysis (at p<0.05).

\section{Ethical issues}

The study was approved by the Tallinn Medical Research Ethics Committee. Before answering the questions, all participants were required to indicate that they understood the aims and methods of the study and that they consented to take part in it. The opening and landing pages included contact information for the principal investigator in case anybody had any further questions related to the study aims and procedures.

\section{Results}

Overall, 430 people began the questionnaire. Of these, $70 \%$ of them $(n=301)$ completed the questionnaire and submitted their answers, and 30\% $(n=129)$ broke off or did not submit at the end of the questionnaire. Those who completed the questionnaire were compared with those who did not for age, first language (Estonian vs Russian), region (city vs countryside) and satisfaction with their economic situation. The only statistically significant difference was related to region, with more people living in the countryside among those who broke off compared with those who completed the questionnaire ( $24 \%$ vs $13 \%$; $p=0.02$ ).

Of the 301 participants who completed the questionnaire, $12 \%(n=36)$ did not meet the inclusion criteria (18 did not live in Estonia, 10 were not MSM, and eight were younger than 18 years of age). Thus the total sample size of MSM was 265 . As our aim was to develop a testing system and recruit MSM, the analysis of factors related to testing during the study uses data only from those $\mathbf{2 6 5}$ men who were eligible. Participant flowchart and drop-out are presented in the Figure.

\section{Participants}

The characteristics of the MSM in the study are presented in Table 1. The median age was 31 years (mean age 33 years; range $18-67$ years; $53 \%$ were older than 30 years), $90 \%$ completed the questionnaire in Estonian, $71 \%$ were from the capital city Tallinn and the surrounding area; $85 \%$ were working full- or parttime, $43 \%$ had higher education; $44 \%$ were in a steady relationship with a man or a woman; $76 \%$ considered themselves homosexual and $24 \%$ bisexual. A total of $98 \%$ had ever had sex, $33 \%$ were CAGE positive and $23 \%$ had used illegal drugs in the last 12 months). The mean internalised homonegativity score was 1.9 (SD 1.2; range $0.2-5.7$ ).

Of the total sample, $70 \%$ had ever been tested for HIV, and $36 \%$ had been tested in the last 12 months. Selfreported HIV-prevalence was $4 \%$.

Fifty-one per cent of the total sample had ever been tested for STIs, $19 \%$ in the last 12 months. $24 \%$ had ever been diagnosed with an STI. $8 \%$ of those who had ever been tested for STIs reported having had anal swabs taken.

$30 \%$ of the total sample had received a full-course vaccination against hepatitis $\mathrm{B}, 3 \%$ had ever had hepatitis B. $18 \%$ of the MSM had received a full-course vaccination against hepatitis $\mathrm{A}$, and $5 \%$ had ever had hepatitis A.

\section{Testing}

A total of 81 men were tested during the study ( $27 \%$ of all those who completed the questionnaire): $68 \mathrm{MSM}$ (testing rate among MSM: 26\%) and 13 non-eligible participants (testing rate among non-eligible participants: $35 \%$ ) (Figure). 74 men (91\%) were tested within one month of completing the questionnaire, three within two months ( $4 \%$ ), and four within four months (5\%).

Of the 68 MSM who were tested, 40 were tested for all infections (59\%), three ( $4 \%$ ) gave only blood and 25 provided only urine samples (37\%). Thus a total of 65 provided urine samples ( $25 \%$ of MSM who completed the questionnaire), and 43 provided blood samples ( $16 \%$ of MSM who completed the questionnaire).

The univariate analysis identified several factors associated with testing among MSM during the study (Table 1). The multivariable logistic regression analysis showed that testing during the study was independently associated with Russian as the first language, living in towns/cities and having ever been tested for HIV (Table 1).

\section{Test results}

The test results are presented in Table 2 . Of the 17 participants positive for HAV antibodies, two had had hepatitis $A$, five had been vaccinated against HAV, four had not been vaccinated and six did not know their 


\section{TABLE 1A}

Participant characteristics, univariate and multivariable analysis of factors associated with biological testing, Internet study of men who have sex with men, Estonia, $2013(n=265)$

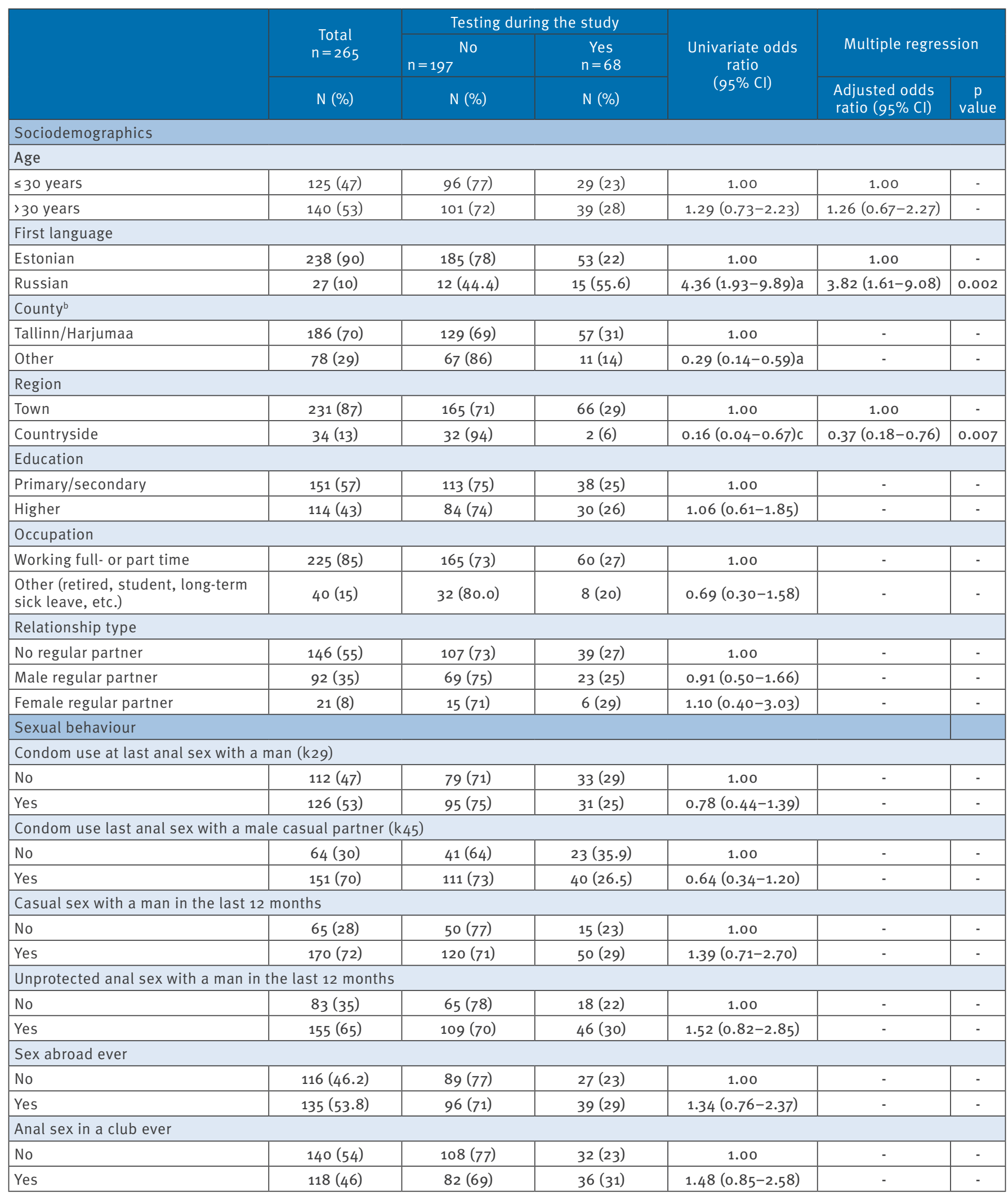

$\mathrm{Cl}$ : confidence intervals; SD: standard deviation; STI: sexually transmitted infection.

a $\mathrm{p}<0.001$

b Was not included in multivariable regression analysis because it was highly correlated to region of living (which included both town and countryside)

p<0.01

d Includes those who have never drunk alcoholic beverages ( $n=11 ; 4.2 \%$ of the participants)

e $p<0.05$ 


\section{TABLE 1B}

Participant characteristics, univariate and multivariable analysis of factors associated with biological testing, Internet study of men who have sex with men, Estonia, $2013(\mathrm{n}=265)$

\begin{tabular}{|c|c|c|c|c|c|c|}
\hline & \multirow{3}{*}{$\begin{array}{c}\begin{array}{c}\text { Total } \\
n=265\end{array} \\
\mathrm{~N}(\%)\end{array}$} & \multicolumn{2}{|c|}{ Testing during the study } & \multirow{3}{*}{$\begin{array}{c}\text { Univariate odds } \\
\text { ratio } \\
(95 \% \mathrm{Cl})\end{array}$} & \multirow{2}{*}{\multicolumn{2}{|c|}{ Multiple regression }} \\
\hline & & \multirow{2}{*}{\begin{tabular}{|r|}
\multicolumn{1}{|c|}{$\mathrm{No}^{\prime}=197$} \\
$\mathrm{~N}(\%)$
\end{tabular}} & \multirow{2}{*}{$\begin{array}{c}\begin{array}{c}\text { Yes } \\
n=68\end{array} \\
N(\%)\end{array}$} & & & \\
\hline & & & & & $\begin{array}{l}\text { Adjusted odds } \\
\text { ratio }(95 \% \mathrm{Cl})\end{array}$ & $\begin{array}{c}\mathrm{p} \\
\text { value }\end{array}$ \\
\hline \multicolumn{7}{|l|}{ Sexual behaviour } \\
\hline \multicolumn{7}{|l|}{ Sex with a woman ever } \\
\hline No & $119(46)$ & $84(71)$ & $35(29)$ & 1.00 & - & - \\
\hline Yes & $140(54)$ & $107(76)$ & $33(24)$ & $0.74(0.43-1.29)$ & - & - \\
\hline \multicolumn{7}{|l|}{ Sexual orientation } \\
\hline Homosexual & $192(76)$ & $139(72)$ & $53(28)$ & 1.00 & - & - \\
\hline Bisexual & $61(24)$ & $49(80)$ & $12(20)$ & $0.64(0.32-1.30)$ & - & - \\
\hline $\begin{array}{l}\text { Internalised homonegativity } \\
\text { (mean, SD) }\end{array}$ & $\begin{array}{c}1.9(\mathrm{SD} 1.2 ; 95 \% \mathrm{Cl} \\
1.8-2.1)\end{array}$ & $\begin{array}{c}1.9(\mathrm{SD} 1.2 ; 95 \% \mathrm{Cl} \\
1.7-2.1)\end{array}$ & $\begin{array}{c}2.1(\mathrm{SD} 1.2 ; 95 \% \mathrm{Cl} \\
1.7-2.3)\end{array}$ & & - & - \\
\hline \multicolumn{7}{|l|}{ Drug and alcohol use } \\
\hline \multicolumn{7}{|c|}{ Illegal drug use in the last 12 months } \\
\hline No & $204(77)$ & $152(75)$ & $52(25)$ & 1.00 & - & - \\
\hline Yes & $61(23)$ & $45(74)$ & $16(26)$ & $1.04(0.54-1.99)$ & - & - \\
\hline \multicolumn{7}{|l|}{ CAGE score [17] } \\
\hline Negative $(0-2) d$ & $178(67)$ & $131(74)$ & $47(26)$ & 1.00 & - & - \\
\hline Positive (3-4) & $87(33)$ & $66(76)$ & $21(24)$ & $0.89(0.49-1.61)$ & - & - \\
\hline \multicolumn{7}{|l|}{ HIV and STI testing and history } \\
\hline \multicolumn{7}{|c|}{ Responses to 'How confident are you that you could get a test for HIV if you wanted one?' } \\
\hline Not so confident & $93(35)$ & $71(76)$ & $22(24)$ & 1.00 & - & - \\
\hline Very confident & $172(65)$ & $126(73)$ & $46(27)$ & $1.18(0.66-2.12)$ & - & - \\
\hline \multicolumn{7}{|c|}{ Responses to 'How confident are you that you could get a test for STIs (other than HIV) if you wanted one? } \\
\hline Not so confident & $130(50)$ & $97(75)$ & $33(25)$ & 1.00 & - & - \\
\hline Very confident & $135(51)$ & $100(74)$ & $35(26)$ & $1.03(0.59-1.79)$ & - & - \\
\hline \multicolumn{7}{|l|}{ STI test ever } \\
\hline No & $126(49)$ & $100(79)$ & $26(21)$ & 1.00 & - & - \\
\hline Yes & $132(51)$ & $93(71)$ & 39 (30) & $1.61(0.91-2.85)$ & - & - \\
\hline \multicolumn{7}{|l|}{ STI test in last 12 months } \\
\hline No & $216(82)$ & $166(7)$ & $50(23)$ & 1.00 & - & - \\
\hline Yes & $49(18)$ & $31(63)$ & $18(37)$ & $1.93(0.99-3.73)$ & - & - \\
\hline \multicolumn{7}{|l|}{ STI ever } \\
\hline No & $202(76)$ & $153(76)$ & $49(24)$ & 1.00 & - & - \\
\hline Yes & $63(24)$ & $44(70)$ & $19(30)$ & $1.35(0.72-2.52)$ & - & - \\
\hline \multicolumn{7}{|l|}{ HIV test ever } \\
\hline No & $79(30)$ & $67(85)$ & $12(15)$ & 1.00 & 1.00 & - \\
\hline Yes & $185(70)$ & $129(70)$ & $56(30)$ & $2.4(1.22-4.83) \mathrm{e}$ & $2.38(1.15-4.94)$ & 0.02 \\
\hline \multicolumn{7}{|l|}{ HIV test in last 12 months } \\
\hline No & $168(63)$ & $130(77)$ & $38(23)$ & 1.00 & - & - \\
\hline Yes & $97(37)$ & $67(69)$ & $30(31)$ & $1.53(0.87-2.69)$ & - & - \\
\hline
\end{tabular}

$\mathrm{Cl}$ : confidence intervals; SD: standard deviation; STI: sexually transmitted infection.

a $p<0.001$

b Was not included in multivariable regression analysis because it was highly correlated to region of living (which included both town and countryside)

p<0.01

d Includes those who have never drunk alcoholic beverages ( $n=11 ; 4.2 \%$ of the participants)

e $p<0.05$ 
Results of biological testing, Internet study of men who have sex with men, Estonia, 2013 ( $\mathrm{n}=265)$

\begin{tabular}{|c|c|c|c|c|c|}
\hline & \multicolumn{2}{|c|}{ Positive } & \multicolumn{2}{|c|}{ Negative } & \multirow{2}{*}{$\begin{array}{c}\text { Total number of } \\
\text { tests } \\
\mathrm{N}\end{array}$} \\
\hline & $\mathrm{N}$ & $\%$ & $\mathrm{~N}$ & $\%$ & \\
\hline Chlamydia trachomatis LGV & - & - & 65 & 100 & 65 \\
\hline C. trachomatis & 1 & 2 & 64 & 98 & 65 \\
\hline Mycoplasma genitalium & - & - & 65 & 100 & 65 \\
\hline Neisseria gonorrhoeae & 1 & 2 & 64 & 98 & 65 \\
\hline Trichomonas vaginalis & - & - & 65 & 100 & 65 \\
\hline Treponema pallidum (antibodies) & 2 & 5 & 41 & 95 & 43 \\
\hline HAV antibodies & 17 & 40 & 26 & 60 & 43 \\
\hline $\mathrm{HBsAg}$ & - & - & 43 & 100 & 43 \\
\hline HCV antibodies & 2 & 5 & 41 & 95 & 43 \\
\hline HIV $1 / 2$ antigen + antibodies & 3 & 7 & 40 & 93 & 43 \\
\hline
\end{tabular}

LGV: lymphogranuloma venereum; HAV: hepatitis A virus; HBsAg: hepatitis B surface antigen; HCV: hepatitis C virus.

vaccination status. HAV antibody prevalence among non-vaccinated men was $32 \%(11 / 34)$. Neither of the two participants who tested positive for HCV antibodies had been aware of their status; one had had blood transfusion before 1994 and one had injected drugs in the past. Three people were HIV-positive, two of whom were already aware of their status. The third man had considered himself HIV-negative, and had last been tested for HIV less than a year previously. As he was willing to provide his personal data for the laboratory (which was not mandatory), his test result was confirmed and he was linked to HIV care in Tallinn.

\section{Discussion}

This was the first attempt in Estonia to collect biological samples for blood-borne and STI marker detection from MSM participating in an Internet-based behavioural study. We recruited 265 MSM, of whom $26 \%$ underwent various types of testing. We detected 4 STI cases, and one new HIV case.

Of the people who began the questionnaire, 30\% broke off before the end. We presume this was most likely due to the length of the questionnaire. To improve this in the future, we will shorten the questionnaire considerably. Those who broke off the questionnaire were more likely to be living in the countryside. One reason may have been perceived difficulties in accessing the testing offered during the study. People living in smaller communities may also have been more worried about confidentiality when ordering the test kits by post.

The overall sample size was smaller compared with EMIS 2010, but more or less comparable to the earlier Internet studies [8-11]. Table 3 presents the main sociodemographic and HIV-testing-related data from the previous studies. Our sample appears to be less diverse compared with previous Internet studies, which recruited a larger proportion of MSM who were bisexual, non-Estonian and lived outside the capital city Tallinn and the surrounding Harju county. The mean age of the participants in different studies has increased somewhat as well as the proportion ever tested for HIV (which may be related to vigorous HIV testing campaigns targeting MSM in recent years).

According to Statistics Estonia, 79\% of households in Estonia had access to the Internet at home in 2013 ( $82 \%$ of those living in towns and $73 \%$ of those living in the countryside). This has improved considerably since 2005 when the respective percentage was $37 \%$ ( $32 \%$ living in towns and $24 \%$ living in the countryside) [17]. We do not have specific data about Internet access among MSM, but we assume it is at least as good as among the general population. Thus the reason for lower sample size is not related to the decreased access to the Internet.

The way in which the survey was promoted may be one of the reasons for the smaller and less diverse sample. With EMIS 2010, for example, the largest recruiters were not national websites but pan-European websites that sent instant messages (IMs) to their members, and $24 \%$ of the Estonian participants in EMIS were recruited through IMs sent by PlanetRomeo [11], which we did not use this time. In 2010, 12 national websites were used for promotion, but this time only 11 were used, only one of which was primarily Russian-language. In the future, participation rates could be improved by better promotion.

Twenty-six per cent of participants were tested for STIs or bloodborne infections. In a population-based survey conducted in Estonia to estimate the prevalence of 
Comparison of sample size, and selected sociodemographic, HIV testing, and HIV prevalence data from studies of men who have sex with men in Estonia, 2004-2013

\begin{tabular}{|c|c|c|c|c|c|c|c|}
\hline \multirow[b]{2}{*}{ Study type } & $2004[7]$ & $2006[8]$ & $2007[9]$ & $2007[16]$ & $2008[6]$ & $2010[10]$ & 2013 \\
\hline & Internet & Internet & Internet & RDS & $\begin{array}{l}\text { Venue- } \\
\text { based }\end{array}$ & Internet & Combination \\
\hline $\begin{array}{l}\text { Number of participants who completed the } \\
\text { questionnaire }\end{array}$ & 358 & 331 & 399 & NA & NA & 629 & 301 \\
\hline Final eligible sample size, n (\%) & $312(87 \%)$ & $232(70 \%)$ & $361(90 \%)$ & 59 & 79 & $594(94 \%)$ & $265(88 \%)$ \\
\hline Mean age of the participants, years & 28 & 27 & 31 & 27 & $30^{a}$ & 32 & 33 \\
\hline Percentage homosexual & 59 & 66 & 67 & 68 & 55 & 65 & 76 \\
\hline Percentage with higher education & 38 & 43 & 40 & 54 & 51 & 45 & 43 \\
\hline Percentage of Estonians & 76 & 60 & 79 & 53 & 71 & 85 & 90 \\
\hline Percentage living in Tallinn and Harju county & 62 & 59 & 66 & 100 & 100 & 60 & 71 \\
\hline Percentage HIV-tested ever during lifetime (\%) & 41 & 47 & 50 & 71 & 68 & 60 & 70 \\
\hline Self-reported HIV-prevalence, n (\%) & NA & NA & NA & NA & $1(1.3 \%)^{b}$ & $10(1.7 \%)^{b}$ & $8(3.0 \%)^{b}$ \\
\hline HIV-prevalence during the study, n (\%) & NA & NA & NA & $1(1.7 \%)^{b}$ & $2(2.5 \%)^{b}$ & NA & $3 / 43(7.0 \%)$ \\
\hline
\end{tabular}

RDS: respondent-driven sampling; NA: not available.

a Median age

${ }^{\mathrm{b}}$ Among all participants eligible for the study

C. trachomatis infection (tests were collected by participants and returned by post) the overall response rate for men was $32 \%$ [22]. In a systematic review of strategies for home-based chlamydia and gonorrhoea screening, the median specimen return rate for postal test kits requested through the Internet or telephone was $32 \%(27-47 \%)$ for the general population [15].

STI testing was used more than blood-borne infections (HIV and hepatitis) testing. It may have been more convenient (a sampling kit could be ordered and returned by post and there was no need to visit a laboratory in person), and more attractive as there have been several HIV testing campaigns for MSM in Estonia, but there are no free-of-charge and anonymous STI testing opportunities [5]. The participants concerned about confidentiality may have considered it also more anonymous.

Testing during the study period was independently associated with Russian as the first language, living in towns/cities and having ever been tested for HIV. No other sociodemographic and behavioural indicators (including recent sexual risk behaviours) were related to testing. Men who had ever been tested for HIV were more likely to test during this study. This may indicate a habit for testing or personal attitudes and values which support testing and/or participation in research projects. Our dependent variable was 'testing during the study'. We did conduct separate analysis for those who were tested only for STIs or for blood-borne infections and also for those who were tested for both, but no other associations were found. One reason could be the very small sample size.
Despite the Internet-based questionnaire and testing sites in six larger cities in Estonia, the vast majority of participants were still from larger cities: the capital city, Tallinn, and surrounding Harju county (population 430,000 ) and the second largest city, Tartu (population size 99,500), as in previous studies [8-11]. Also, most of the MSM tested were from Tallinn ( $n=57 ; 84 \%)$, eight men were from Tartu and three from other regions. It may be related to the fear of being identified as gay or testing for STIs in general in smaller communities. The proportion of gay people in smaller communities may be very low, as many gay people may choose to move to the capital city, where they can be more anonymous and also experience less stigma.

The sample size for testing $(n=68)$ was comparable with the previous studies $[7,18]$. As time and resources are at a premium in case of limited resources for active surveillance, we consider that one of the advantages of our approach lay in using the existing laboratory network. Thus we avoided the costs related to setting up special study sites and engaging personnel (as was the case with RDS and venue-based studies). The selfcollection of urine samples worked well: all samples sent to the laboratory were suitable for processing. We received no complaints from the participants. The vast majority (91\%) were tested within one month of answering the questionnaire.

We detected one case each of gonorrhoea and chlamydia (not LGV). No LGV cases have yet been reported in Estonia [3]. The limitation of our project was STI testing only from urine samples, so possible rectal and pharyngeal STI cases were missed. 
HAV antibody prevalence among non-vaccinated men was $32 \%$. This prevalence rate is in accordance with the previous studies. According to Tefanova and colleagues [23], the prevalence of hepatitis A among 20-29 year olds in Estonia was 41\%. According to the World Health Organization, the proportion of people in eastern Europe who are immune to hepatitis $A$ by the age of 40 years is $75 \%$ [24].

Self-reported HIV prevalence was $4 \%$, and $7 \%$ of the men who were tested for HIV during the study were found to be positive. Both rates are somewhat higher than in previous studies $[6,18]$. Unfortunately, our sample size was too small for us to make definite conclusions about HIV trends among MSM in Estonia. However, the data on self-reported sexual behaviours show that many participants take risks, and so there is a possibility for further spread of HIV and other STIs among MSM.

MSM are not a priority group for HIV prevention in Estonia. The Internet, which provides a useful venue for delivering HIV/STI prevention and safer sex messages to MSM, could be better used, especially since gay-oriented bars, clubs and saunas (where condoms and lubricants are provided for free) only reach MSM in Tallinn and those MSM who are most likely to be open about being gay [5]. Considering that there are no gayfriendly sexual health services in Estonia, the system we have developed may be exploited in the future as an alternative venue for anonymous and free-of-charge STI and blood-borne infection testing among MSM. It could be further expanded by including sample kits for rectal and pharyngeal swabs, and also HIV home-test kits (currently not available in Estonia).

\section{Limitations}

One limitation of this study is that it was cross-sectional and we used a non-random sample. People who may have been more likely to participate include those with better-than-average access to the Internet, those who were more comfortable with technology, and those who were interested in free testing. The data were self-reported, and social desirability as well as recall bias may have been involved. In order to secure the anonymity of our participants we did not collect IP addresses, and so it was possible for one person to submit two or more questionnaires.

\section{Conclusions}

Linking Internet-based behavioural data collection with biological sample collection is a promising approach for studying hard-to-reach populations and merits further development. Further research is needed to determine the characteristics of people who opt to test in such studies and thereby the representativeness of the prevalence data. Considering the high prevalence of risk behaviours and low testing rates, higher priority to MSM sexual health should be given when planning HIV/STI prevention strategies.
Acknowledgements

The authors gratefully acknowledge the contribution of the following individuals: Juta Teller for help in designing the web-based questionnaire, Julia Hristojeva and Julia Vinckler for their help in adapting the Russian version of the questionnaire, Rain Uusen and Aare Raudsepp for their input in questionnaire development, Tanel Kreek in developing promotional materials, and Elizabeth Hoile for editing the manuscript.

This work has been supported by the National Institute for Health Development, Estonia, from Estonian Research Council Health promotion research programme TerVE (grant number 3.2.1002.11-0002) and National HIV/AIDS Strategy for 2006-2015.

\section{Conflict of interest}

None declared.

Authors' contributions

$K R, L L$ and J designed the study. KR supervised the data collection. KR and LL designed the data analysis and LL conducted the statistical analysis. KR wrote the first draft of the manuscript. All of the authors contributed to the final version of the manuscript. All of the authors read and approved the final manuscript.

\section{References}

3. European Centre for Disease Prevention and Control/ WHO Regional Office for Europe. HIV/AIDS surveillance in Europe 2013. Stockholm: ECDC; 2014. Available from: http://ecdc. europa.eu/en/publications/Publications/hiv-aids-surveillancereport-Europe-2013.pdf

4. European Centre for Disease Prevention and Control (ECDC). Sexually transmitted infections in Europe 2012. Stockholm: ECDC; 2014. http://www.ecdc.europa.eu/en/publications/ Publications/sexually-transmitted-infections-europesurveillance-report-2012.pdf

5. Health Board. Estonia. Available from http://www.terviseamet. ee/nakkushaigused/nakkushaigustesse-haigestumine.html

6. Marcus U, Hickson F, Weatherburn P, Schmidt AJ; EMIS Network. Estimating the size of the MSM populations for 38 European countries by calculating the survey-surveillance discrepancies (SSD) between self-reported new HIV diagnoses from the European MSM internet survey (EMIS) and surveillance-reported HIV diagnoses among MSM in 2009. BMC Public Health. 2013;13(1):919. http://dx.doi.org/10.1186/14712458-13-919 PMID:24088198

7. Rüütel K, Trummal A, Salekešin M, Pervilhac C. HIV Epidemic in Estonia: Analysis of Strategic Information. Case Study. WHO Regional Office for Europe; 2011.

8. Johnston LG, Trummal A, Lohmus L, Ravalepik A. Efficacy of convenience sampling through the internet versus respondent driven sampling among males who have sex with males in Tallinn and Harju County, Estonia: challenges reaching a hidden population. AIDS Care. 2009;21(9):1195-202. http:// dx.doi.org/10.1080/09540120902729973 PMID:20024780

9. Tripathi A, Rüütel K, Parker RD. HIV risk behaviour knowledge, substance use and unprotected sex in men who have sex with men in Tallinn, Estonia. Euro Surveill. 2009;14(48):1942. PMID:20003896

10. Lõhmus L, Trummal A. HIV/AIDS-iga seotud teadmised ja käitumine gay-internetilehekülgi külastavate meeste seas, 2004. [Knowledge and risk behaviours related to HIV-infection among men visiting gay-related web sites: study report 2004]. Tallinn, National Institute for Health Development; 2004. Estonian. Available from: http://www.tai.ee/et/terviseandmed/ uuringud/download/21

11. The EMIS Network. EMIS 2010: The European Men-Who-HaveSex-With-Men Internet Survey. Findings from 38 countries. Stockholm: European Centre for Disease Prevention and Control 2013. Available from http://ecdc.europa.eu/en/ publications/Publications/EMIS-2010-european-men-whohave-sex-with-men-survey.pdf 
12. Domeika M, Oscarsson L, Hallén A, Hjelm E, Sylvan S. Mailed urine samples are not an effective screening approach for Chlamydia trachomatis case finding among young men. J Eur Acad Dermatol Venereol. 2007;21(6):789-94. http://dx.doi. org/10.1111/j.1468-3083.2006.02088.x PMID:17567309

13. Chai SJ, Aumakhan B, Barnes M, Jett-Goheen M, Quinn N, Agreda P, et al. Internet-based screening for sexually transmitted infections to reach nonclinic populations in the community: risk factors for infection in men. Sex Transm Dis. 2010;37(12):756-63. http://dx.doi.org/10.1097/ OLQ.obo13e3181e3d771 PMID:20644498

14. Gaydos CA, Barnes M, Aumakhan B, Quinn N, Agreda P, Whittle $P$, et al. Can e-technology through the Internet be used as a new tool to address the Chlamydia trachomatis epidemic by home sampling and vaginal swabs? Sex Transm Dis. 2009;36(9):577-80. http://dx.doi.org/10.1097/ OLQ.ob013e3181a7482f PMID:19543145

15. Jamil MS, Hocking JS, Bauer HM, Ali H, Wand H, Smith K, et al. Home-based chlamydia and gonorrhoea screening: systematic review of strategies and outcomes. BMC Public Health. 2013;13(1):189. http://dx.doi.org/10.1186/1471-2458-13189 PMID:23496833

16. Wood M, Ellks R, Grobicki M. Outreach sexual infection screening and postal tests in men who have sex with men: are they comparable to clinic screening? Int J STD AIDS. 2014; pii:0956462414539668. PMID:24912535

17. Statistics Estonia. Statistical Database. Available from http:// pub.stat.ee/px-web.2001/Dialog/statfile1.asp

18. Trummal A, Johnston LG, Lõhmus L. HIV prevalence and risk behaviours among men having sex with men in Tallinn: pilo study using respondent driven sampling. Tallinn, National Institute for Health Development; 2007. Available from: http:// www.tai.ee/et/terviseandmed/uuringud/download/75

19. Ewing JA. Detecting alcoholism. The CAGE questionnaire. JAMA. 1984;252(14):1905-7. http://dx.doi.org/10.1001/ jama.1984.03350140051025 PMID:6471323

20. Smolenski DJ, Diamond PM, Ross MW, Rosser BRS. Revision, criterion validity, and multigroup assessment of the reactions to homosexuality scale. J Pers Assess. 2010;92(6):56876. http://dx.doi.org/10.1080/00223891.2010.513300 PMID:20954058

21. Ross MW, Kajubi P, Mandel JS, McFarland W, Raymond HF. Internalized homonegativity/homophobia is associated with HIV-risk behaviours among Ugandan gay and bisexual men. Int J STD AIDS. 2013;24(5):409-13. http://dx.doi. org/10.1177/0956462412472793 PMID:23970711

22. Uusküla A, Kals M, Denks K, Nurm U, Kasesalu L, Dehovitz J, et al. The prevalence of chlamydial infection in Estonia: a population-based survey. Int J STD AIDS. 2008;19(7):455-8. http://dx.doi.org/10.1258/ijsa.2008.007325 PMID:18574116

23. Tefanova V, Tallo T, Katargina O, Priimägi L. Shift in seropidemiology of hepatitis A in Estonian population. Proceedings of the 7 th Nordic-Baltic Congress on Infectious Diseases; 2006 Sep 18-20, 2006; Riga, Latvia.

24. Jacobsen $\mathrm{KH}$. The global prevalence of hepatitis A virus infection and susceptibility: a systematic review. World Health Organization; 2010. Available from: http://whqlibdoc.who.int/ hq/2010/WHO_IVB_10.01_eng.pdf 